\section{$\underset{\substack{\text { hommes } \\ \text { \& migrations }}}{ }$}

\section{Hommes \& migrations}

Revue française de référence sur les dynamiques

migratoires

\section{$1322 \mid 2018$}

Exposer les migrations

\title{
Des Figues en avril
}

Film français, Coq Héron productions, 2018, de Nadir Dendoune.

\section{Catherine Guilyardi}

\section{(2) OpenEdition \\ 12 Journals}

Édition électronique

URL : https://journals.openedition.org/hommesmigrations/6899

DOI : 10.4000/hommesmigrations.6899

ISSN : 2262-3353

Éditeur

Musée national de l'histoire de l'immigration

Édition imprimée

Date de publication : 1 juillet 2018

Pagination : 210

ISBN : 978-2-919040-42-1

ISSN : 1142-852X

Référence électronique

Catherine Guilyardi, «Des Figues en avril », Hommes \& migrations [En ligne], 1322 | 2018, mis en ligne le 01 juillet 2018, consulté le 21 janvier 2022. URL : http://journals.openedition.org/hommesmigrations/ 6899 ; DOI : https://doi.org/10.4000/hommesmigrations.6899 


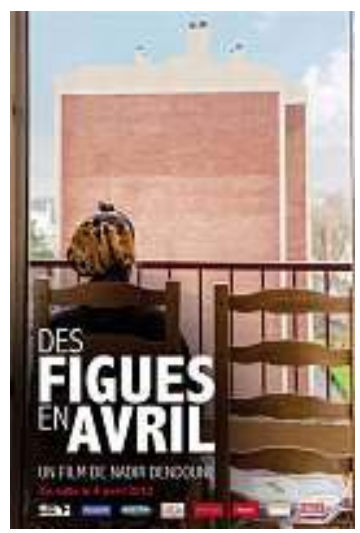

\section{Nadir Dendoune}

Des Figues en avril

Coq Héron Productions, 2018

Nadir Dendoune nous émeut dans ce documentaire qui raconte une histoire universelle. On connait le chroniqueur provocateur et engagé du Courrier de l'Atlas, l'écrivain à l'écriture ciselé dont le récit, Un tocard sur le toit du monde, a inspiré le film L'Ascension, en 2017 ; on a lu Nos rêves de pauvres sur le courage de ses parents kabyles immigrés en France, le père jardinier, la mère qui élève ses 9 enfants dont Nadir, 45 ans aujourd'hui. Dans ce documentaire filmé comme un document amateur, on suit le regard admiratif d'un fils pour sa mère de 82 ans dont la vie fut de prendre soin des autres. Ici, le chroniqueur au francparler et aux mots crus s'efface.

Dans sa petite cuisine d'une cité du 93, Messaouda Dendoune fait des gestes mille fois répétés et que l'on reconnaît, comme lorsque ses mains façonnent la semoule de blé. Elles pourraient nettoyer le riz ou travailler le mil, si elle était turque ou malienne. Son langage aussi, mélange de français et de sa langue natale, le kabyle, rappelle celui d'autres femmes qui suivirent leur mari immigré en France. Elle rejoint le sien à 25 ans, déjà mère de quatre filles. Soixante ans plus tard, l'exil ne semble pas avoir altéré son identité nationale ni sociale. Elle se dit «100\% kabyle » et ne regrette pas de ne pas être bourgeoise "pour manger dehors tous les jours". "Nous sommes des paysans", précise-t-elle à son fils qui lui suggère "nous sommes des banlieusards ". Elle est fière de son mari, un «bosseur qui sait travailler la terre » et qui n’a jamais connu le chômage.

Les questions du fils sont parfois indiscrètes et, même si elle se livre volontiers à celui qu'elle fixe avec un regard malin et tendre, elle sait poser ses limites, notamment quand il passe le seuil de sa chambre. On devine Nadir intimidé lorsqu'il filme sa mère nouant ses longs cheveux teints au henné à un foulard coloré qu'elle enroule autour de sa tête. Elle se prépare pour aller voir son mari car elle ne passera "pas une journée sans voir (son) homme". "Monsieur Dendoune ", "le père " ou "le vieux", comme l'appelle Messaouda, est en maison de retraite. Il a tout oublié de sa vie et des siens, ou presque, mais sa femme prend soin de lui, comme elle l'a fait pendant sept ans à domicile. "Chez nous, on n'abandonne pas (...), j'irai jusqu'à ce que je puisse plus marcher. " Des Figues en avril, dont le titre raconte l'étonnement de Messaouda d'avoir vu des figues de barbarie en avril en Australie, dit la solitude de celle qui reste. Pourtant, ce n'est pas un film triste. Même si le projet de retour nourri pendant toute une vie d'exil ne se fera jamais, cette femme semble habitée par mille vies, celles des siens - enfants, petits-enfants et surtout son mari qui a toujours besoin d'elle - et celles de ses ancêtres, et surtout de sa Kabylie natale. Messaouda sait qui elle est et s'inquiète plutôt pour la jeune génération à qui elle souhaite bon courage. I

Un tocard sur le toit du monde, Paris,

J.-C. Lattès, 2010.

Nos rêves de pauvres, Paris, J.-C. Lattès, 2017.

Catherine Guilyardi 